\title{
Road Network Equilibrium Approaches to Environmental Sustainability
}

Environmental sustainability is closely related to transportation, especially the road network, because vehicle emissions and noise damage the environment and have adverse effects on human health. It is therefore important to take their effect into account when designing and managing road networks. Road network equilibrium approaches have been used to estimate this impact, and to design and manage road networks accordingly. However, no comprehensive review has summarized the applications of these approaches to the design and management of road networks that explicitly address environmental concerns. More importantly, it is necessary to identify this gap in the literature so that future research can improve existing methodologies. Hence, this paper summarizes these applications, and identifies potential future research directions in terms of theories, modeling approaches, algorithms, analyses, and applications.

Keywords: road network equilibrium; environmental sustainability; bi-level transport problems; traffic assignment; vehicle emission models; noise models

\section{Introduction}

There is no universally accepted definition of environmental sustainability (ES). Voet et al. (2000) stated that ES “is guaranteed when environmental interventions are kept within the limits of the environmental carrying capacity”. Sutton (2004) referred to ES as the ability to maintain the qualities that are valued in the physical environment, which includes the natural and biological environments. Stead (2008) indicated that ES “means maintaining the integrity, productivity, and resilience of biological and physical systems, and preserving access to a healthy environment”. Although these definitions differ from one another, they all incorporate the concept of maintaining the quality of the environment.

ES is closely related to transportation, and in particular road transportation, because motor vehicles traveling on roads emit emissions and noise, which impoverish the environment. While it is difficult to estimate the proportion of noise generated by road transport, the quantities of vehicle emissions are known to be large. For example, it was 
estimated that in Hong Kong over 80\% of carbon monoxide (CO), 20\% of nitrogen oxide and $30 \%$ of particular matter in the atmosphere were found to emanate from road transport in 2007 (HKSAR Environmental Protection Department, 2007)

Both vehicle emissions and noise can have adverse effects on human health (Cappiello, 2002). Moreover, carbon dioxide is not only one of the major vehicle emissions, but also a greenhouse gas that contributes to global warming (Cappiello, 2002). It is therefore important to control the quantities of vehicle emissions and the level of traffic noise generated to reduce the impact of road transport activities on the environment and human health. Other than the overall emissions and noise levels, their spatial and temporal distributions need to be controlled, since these distributions are associated with an issue called environmental equity.

Road network equilibrium approaches have been used to estimate vehicle emissions and noise, and accordingly to design or plan road networks that take ES and environmental equity into account. These approaches rely on road network equilibrium models to distribute traffic onto the road network before the associated vehicle emissions and noise can be determined and environmentally sustainable road networks can be designed through the formulation of bi-level problems. In particular, equilibrium approaches rely on equilibrium travel choice principles to depict route choice of drivers and sometimes their departure time and mode choices as well. An advantage of equilibrium approaches over several other types of optimization approaches is that equilibrium approaches are capable of capturing travel choice behavior and also the response of drivers as a result of the implementation of transportation planning and traffic management policy. For example, these approaches can capture how the driver changes his/her route as a result of adding new roads to the transport network. Compared with empirical models, equilibrium approaches can also depict the vehicle emissions and noise of the system at a network level, not only at the link or route 
level. However, to date no review has summarized the use of road network equilibrium approaches with regard to environmental sustainability or equity. More importantly, it is necessary to recognize this gap in the literature so that potential research directions on such approaches can be identified in order to improve the current methodologies. Therefore, the objective of this paper is to summarize the literature and to indicate these potential future research directions.

This review also deals with the estimation of vehicle emissions and noise, which are a key component in the planning of environmentally sustainable transport networks. Therefore, for the sake of completeness, we have included a review of these models with some updates. However, because these have been reviewed very recently, we only address them briefly and focus on their input requirements and their linkage with equilibrium models. We also propose a new classification for both classes of models, in which terminologies are consistent with those of traffic assignment (TA).

The remainder of this paper is organized as follows. The next section provides a brief review of road network equilibrium modeling approaches, which is followed by a review of approaches to estimate vehicle emissions and noise; the fourth section reviews traffic assignment studies that explicitly address environmental concerns; the fifth section discusses bi-level transportation problems and the literature on network designs that considered ES; and finally, the last section presents some potential future research directions.

\section{Road network equilibrium modeling approaches}

Road network equilibrium modeling approaches rely on road network equilibrium models, or TA models, to distribute traffic onto the road network and determine the flow on each link of the network. These models can generally be classified into two categories namely, dynamic and static models. Dynamic TA (DTA) models take the departure time of 
travelers and the temporal evolution of flow on the links into account, whereas static TA (STA) models do not. However, both types of models consist of two major components namely, the traffic equilibrium principle and the traffic flow component.

\section{Traffic equilibrium principles}

Traffic equilibrium principles determine the traffic level on each road in a network. They vary on the assumptions and the measures used to define equilibrium. The two classical principles for STA are: (1) Wardrop’s first principle or the user-equilibrium (UE) principle; and (2) Wardrop’s second principle or the system optimal (SO) principle (Wardrop, 1952). These principles assume that each traveler knows the exact time he/she will spend on traveling. Although these principles can be extended to consider generalized travel costs rather than travel time, they may not be realistic in most situations.

To capture more realistic travel behavior, dynamic, stochastic, reliability-based and tolerance extensions of Wardrop’s principles have been proposed. The dynamic extension (e.g., Vickrey, 1969) considers the departure time of travelers and can be used in DTA. The stochastic extension (e.g., Daganzo and Sheffi, 1977) relaxes the Wardrop’s assumption that drivers know the travel time of each path exactly. The reliability-based extension (e.g., Hall, 1993; Chan and Lam, 2005; Lo et al., 2006; Szeto et al., 2006, 2009a; Chen and Zhou, 2010; Lam et al., 2010; Szeto, 2011; Zhang et al., 2011) provides for the fact that travel time is uncertain and travelers can leave earlier to counter this uncertainty and avoid late arrivals. The tolerance-based extension, such as the boundedly rational user equilibrium (BRUE) (see Mahmassani and Chang, 1987; Szeto and Lo, 2006a for details), is based on the concept of 'bounded rationality' (Simon, 1955), which is used to describe rational choices that take into account the limitations of the decision-maker in terms of knowledge, computational capacity and the time needed to make decisions (Simon, 1997). This term also refers to the rational 
principles that underlie the non-optimizing adaptive behaviors of real people. A recent focus of equilibrium principles has been on the reliability-based extension and its combination with the stochastic or dynamic extension (e.g., Shao et al., 2006; Chen et al., 2011a; Szeto et al., 2011). A detailed recent review on traffic equilibrium principles can be found in Szeto and Wong (2011).

\section{Traffic flow components}

The traffic flow component depicts how traffic propagates inside a road network and, hence, governs the network performance in terms of travel time. The traffic flow component can be modeled as a unique mapping of route or path flows that yields route travel times. For DTA, the unique mapping can be achieved by using dynamic traffic flow models, which can be classified as microscopic, macroscopic, and mesoscopic (Abdulhai and Kattan, 2004). These three types of models differ in flow representation and in the level of detail of the representation of actual traffic behavior. Microscopic models describe vehicles individually with explicit consideration of their individual trajectories and detailed driving behavior, such as lane changing, acceleration, and overtaking. Macroscopic models represent traffic as fluid and mainly consider the macroscopic relationship between speed, flow and density when describing flow propagation. No trajectories are traced and no detailed driving behavior is modeled. Mesoscopic models group a number of vehicles with the same characteristics into a packet, and the trajectory of each packet is traced similarly to microscopic models. The macroscopic flow-density relationship is used to model flow propagation between links as in the macroscopic models.

\section{Traffic equilibrium models}

Each DTA model consists of a dynamic traffic flow component and a dynamic extension of equilibrium principle, whereas each STA model consists of a traffic flow 
component and the equilibrium principle that disregards the time dimension. Both types of models can be developed by at least five approaches:

- the variational inequality problem approach (e.g., Smith, 1979),

- the non-linear complementarity problem approach (e.g., Aashtiani, 1979),

- the fixed-point problem approach (e.g., Asmuth, 1978),

- the mathematical programming approach (e.g., Beckmann et al., 1956), and

- the continuum modeling problem approach (e.g., Beckmann, 1952; Jiang et al., 2011).

The equivalency between the first four approaches has been discussed in Nagurney (1993).

\section{Vehicle emissions and noise models}

Emission and noise levels are closely related to traffic flow, traffic composition, travel speed, and fuel consumption, which can be estimated from TA models:

- traffic flow and composition can be obtained directly from TA models;

- average speed can be determined once the travel time and the corresponding travel distance are obtained from TA models;

- $\quad$ speed-time profiles can be obtained directly from some TA models (i.e., those that incorporate micro-simulation models);

- $\quad$ space-mean speed can be deduced from the speed-time profiles; and

- fuel consumption can be estimated with the aid of a fuel consumption model that takes information from TA models, such as travel distance and speed changes.

The above traffic flow and speed information can be used together with other inputs to estimate vehicle emissions (noise) through appropriate emission (noise) models. This section reviews existing vehicle emission and noise models, focusing on their inputs, and develops a new classification for both types of models based on whether the temporal 
dimension and details of speed information are required. The main reasons for developing a new classification for both types of models are: firstly, the speed details required by these models are closely related to the TA model adopted. More accurate emission and noise modeling approaches require micro-simulation-based TA models to determine detailed speed-time profiles for input into emission and noise models. Secondly, the classifications for emission and noise models are mutually consistent with each other and are also consistent with TA terminologies, making them easier for readers to follow.

\section{Vehicle emission estimation models}

Emission models determine vehicle emissions by multiplying an emission factor by the corresponding travel activity data such as travel distance, fuel consumed etc., in which the emission factor can be calibrated using chassis (or engine) dynamometer measurements and regression analysis. Reviews on vehicle emission models have been published (e.g., Hickman et al., 1999; Cappiello, 2002; Boulter et al., 2007; Chiou and Chen, 2010; Smit et al., 2010; Wismans et al., 2011). However, their classifications varied. Table 1 summarizes the existing emission models based on our classification — namely aggregated, static, and dynamic approaches — and these are further categorized based on the classification of Smit (2006), which is one of the most comprehensive classifications available in the literature.

\section{Aggregated emission models}

Aggregated emission models need traffic flow, traffic composition, and travel distance from any TA models or from other national annual statistical sources as inputs. The time scale considered is normally in terms of years or months. These models are mainly used for national or regional inventories, the spatial scale of which is large. These models can be further divided into area-wide (or national) emission models and fuel-based emission models. The former uses an aggregate emission factor $(\mathrm{g} / \mathrm{km})$ for the whole study area whereas the 
latter uses the emission factor expressed as grams of pollutant emitted per kilogram of fuel consumed.

\section{Static emission models}

Unlike aggregated models, static emission models or simple speed-based models rely on the speed information obtained from STA models, although the more complicated DTA model can also provide this information. These simple speed-based models can determine emissions at the link level in addition to those at the network, regional or national level. However, since almost all STA models are developed mainly for transportation planning purposes rather than for environmental regulatory purposes, the average speed obtained cannot truly reflect the speed changes of vehicles but is used by average speed models for estimating overall emissions, leading to inaccurate estimates in general. The time scale is normally in terms of hours, which is smaller than that for the aggregated models, but is still longer than that for dynamic emission models (i.e., a time scale in terms of seconds). As shown in Table 1, simple speed-based emission models include average speed models, adjusted average speed models, traffic situation models, queuing emission models, and modal models. These five types of models have different input requirements, in particular those on speed information. Moreover, within the same class of models, inputs can vary from model to model. Hence, Table 1 only shows the inputs that are required by at least one model.

Average speed models are developed based on the principle that the road-type specific emission factor ( $\mathrm{g} / \mathrm{veh} / \mathrm{km}$ or $\mathrm{g} / \mathrm{km}$ ) for a particular pollutant and a given type of vehicle varies according to the average speed during a trip (Boulter et al., 2007).

Adjusted (or corrected) average speed models rely on correction factors to modify the emission factor determined from average speed.

Traffic situation models can be further classified into qualitative and quantitative 
(Smit, 2006). Qualitative traffic situation models use verbal descriptions to depict traffic situations, which are inputs for the emission factor $(\mathrm{g} / \mathrm{km})$. The variables that represent traffic situations (i.e., traffic situation variables) depend on the model, but are usually related to the congestion level (e.g., free flow, stop and go), road type (e.g., arterial, motorway), speed limit (with a $120 \mathrm{~km} / \mathrm{h}$ speed limit), and area type (e.g., outside or inside a built-up area).

Quantitative traffic situation models use quantitative variables to describe traffic situations. In particular, the U.S. Environmental Protection Agency (US EPA) uses mean travel speed for the congestion level whereas the Netherlands Organization for Applied Scientific Research (TNO) uses space mean speed, speed limit, and traffic volume to define the congestion level. The TNO also requires the number of lanes and the length of links to define traffic situations. Queuing emission models require information on signal settings, free flow speed and the type of intersection to determine the change in queue length over time, which is used to predict the time spent for each of the four fundamental driving modes — namely idling, acceleration, deceleration, and cruising. One emission factor $(\mathrm{g} / \mathrm{s})$ is associated with each mode.

Modal emission models (or fundamental driving mode models) assign an emission factor (g/s or g/km) for each driving mode but the inputs for each mode (i.e., modal variables), such as the numbers of major stops and queue move-up, delays, and distribution of mode, can be obtained from the field or the STA models with detailed predictions of queues and delays.

\section{Dynamic emission models}

Dynamic emission models require the speed-time profiles or instantaneous driving pattern data from DTA models. They can be used for detailed temporal and spatial analyses of emissions, and can be classified into speed and speed fluctuation emission models and 
instantaneous models.

Speed and speed fluctuation models incorporate variables that reflect average speed and average speed fluctuation (e.g., acceleration or deceleration) over time, which can only be deduced from the speed-time profiles obtained from DTA models.

Instantaneous emission models also require speed-time profiles and vehicle-specific parameters as inputs. These models can be further classified into four types:

- instantaneous acceleration-speed matrix models (e.g., DRIVE-MODEM (Joumard et al., 1995)), in which the instantaneous emission factors are defined by both instantaneous speed and acceleration that are presented in matrix/table form and deduced from the speed-time profiles;

- $\quad$ instantaneous speed/load matrix models (e.g., PHEM (Zalinger et al., 2005)), in which the emission factors are defined by both engine speed and load that are presented in matrix form, and are in turn functions of road gradient, gear shift, gear ratio, and speed-time profiles;

- instantaneous analytical speed-acceleration function models (e.g., Modal Analysis Model (Kunselman et al., 1974)), in which emission factors are functions of speed and acceleration; and

- $\quad$ instantaneous power-based models (e.g., the Comprehensive Modal Emissions Model (Scora and Barth, 2006)), in which variables related to engine power, such as engine capacity, power generation efficiency, vehicle mass, and vehicle frontal area, are used as additional inputs in comparison with instantaneous analytical speed-acceleration function models.

The accuracy of estimates obtained from dynamic emission models depends on the accuracy of the time-speed profiles obtained from DTA models. However, the DTA models always require a lot of data for calibration and validation, and some of them such as vehicle 
type and age for each origin-destination pair can be difficult and very expensive to obtain precisely. Hence, dynamic emission models may not be able to give accurate emissions estimates.

\section{Noise prediction models}

Some principal factors that are normally taken into account when developing noise prediction models are traffic flow, traffic composition, average speed, measure distance, and the characteristics of the road, such as the gradient and type of the road surface. Steele (2001) provided a critical review of some commonly applied traffic noise prediction models. Quartieri et al. (2009) presented a quantitative review of those most commonly used in Europe and exploited their main features and peculiarities. This section summarizes the three main categories of noise prediction models — namely, aggregated, static, and dynamic noise prediction models.

\section{Aggregated noise prediction models}

Aggregated noise prediction models mainly rely on regression analysis of noise data to develop statistical noise prediction models. One of the oldest models was reported in the Handbook of Acoustic Noise Control (Anon., 1952), and determined $L_{50}$, where $L_{m}$ is the noise level exceeded for $m \%$ of the measurement duration. This sound level is modeled as a log function of traffic volume and the distance from the observation point to the centre of the traffic lane, and vehicle and road types are not specified. Nickson (1965) and Lamure (1965) improved the original model using a parameter that linked the model with experimental data.

Josse (1972) proposed a model to determine the equivalent noise level or average noise level, $L_{e q}$, which is the level of a hypothetical time-invariant noise that would produce the same noise energy as the measured time-varying noise during the same period. Other model inputs are traffic volume and distance. The French Centre Scientifique et Technique du 
Batiment (1991) developed a model to estimate the equivalent sound level, $L_{e q}$, based on $L_{50}$, in which $L_{50}$ is calculated by considering only equivalent vehicle flows, which are also log functions of traffic volume and distance.

Burgess (1977) proposed two models based on $L_{10}$ and $L_{e q}$ as two sound level descriptors. The two models consider not only traffic volume and distance from the traffic but also the percentage of heavy vehicles as inputs.

Quartieri et al. (2009) proposed a general expression of the equivalent sound level that can deduce all the previously mentioned noise prediction models as special cases. This model considers traffic volume, distance, the percentage of heavy vehicles and the acoustic equivalent of heavy vehicles on the link (i.e., the number of light vehicles that produces the same acoustic noise as a heavy vehicle on that link). This number can be estimated by both the regression method and single vehicle emission measurements.

Some models have been proposed to consider the effect of composition of traffic on the noise level, not just the percentage of heavy vehicles, traffic volume and distance. For example, Cvetković et al. (1997) developed a model to determine $L_{e q}$ as a function of the numbers of light vehicles, heavy vehicles and buses. Fagotti and Poggi (1995) further incorporated the number of motorcycles to determine $L_{e q}$.

\section{Static noise prediction models}

The earliest static (or average speed-based) noise prediction models were also developed based on regression analysis but they considered the average speed of vehicles as an additional factor. For example, Johnson and Saunders (1968) presented a model to take into account the mean speed of vehicles in addition to distance and traffic flow, assuming that the percentage of heavy vehicles is $20 \%$. Later, Galloway et al. (1969) improved this by incorporating the percentage of heavy vehicles into the resultant model as an additional 
independent variable.

Subsequent average-speed models focused on the inclusion of additional factors that affect noise prediction. Table 2 compares the inputs required and factors considered by recent models. All of these models not only consider the effects of speed and distance, the flow mix, the gradient of the road, the type of road surface, the nature of the ground surface between the edge of the carriageway and the measurement location, and the presence of buildings, walls and barriers, but also include other considerations. For example, RLS considers car parks, the time-of-day effect and the speed limit.

It should be noted that not all of these models were developed purely on the basis of a statistical approach. Some models, such as MITHRA, have adopted the theory of physics (e.g., ray tracing or beam tracking) in predicting noise propagation to improve the accuracy of predictions.

\section{Dynamic noise prediction models}

Unlike the previous two approaches, these models take into account dynamic traffic flow characteristics, such as variations in speed and flow over time. This approach requires dynamic traffic flow models together with advanced speed-based noise prediction models, such as ASJ, for the estimation of traffic noise at every time step (usually $1 \mathrm{~s}$ ). The dynamic traffic flow models used are either macroscopic (e.g., Leclercq and Lelong, 2001; Lelong and Leclercq, 2003) or microscopic (e.g., De Coensel, 2005; Bhaskar et al., 2007; Chevallier et al., 2009; Can et al., 2010; Tsukui et al., 2010). The former (latter) is normally used to predict noise from roads without traffic signals (signalized intersections or roundabouts). Mesoscopic models have not been used for noise prediction to the best of our knowledge. 


\section{Traffic assignment with environmental considerations}

TA models with environmental considerations can be broadly classified into three categories, namely models with environmental objectives, models with environmental constraints, and models for environmental impact assessment (EIA).

\section{Models with environmental objectives}

Environmental objectives have been captured in TA models through using emissionbased assignment principles. They can be considered as extensions from UE and SO principles. One line of research purely considered emissions as the only objective. For example, Rilett and Benedek (1994) proposed two concepts, the first of which can be considered as an extension to SO, which is referred to as emission optimum (EO). Travelers select routes to ensure that the total environmental impact (noise or emissions) rather than total travel time is minimized. The second concept was based on an extension of UE. Travelers select routes based on travel costs, which include the toll charges that represent the impact on the environment. The first concept was based on the need of the system as a whole, whereas the second concept was based on the need of individual drivers. Benedek and Rilett (1998) found that the EO assignment under congested conditions can result in about 7\% CO reduction compared to the UE and SO assignments. Sugawara and Niemeier (2002) further found that the reduction depends on the level of congestion. When the network is uncongested, the reduction can be more than 20\%. Using microsimulation for finding speed profiles, Ahn and Rakha (2008) found that the EO assignment can reduce CO emissions up to 92\% of CO emissions over the UE and SO assignments.

Another line of research was Rilett and Benedek (1994) which focused on environmental equity. It can be considered as an extension of UE, in which vehicles are routed in such a way that the amount of emissions or noise released on all streets (or a subset 
of streets) is the same. Under this TA, no group of residents near the traffic network is affected more than any other group.

Multiple objectives including environmental objectives have been studied in the SO framework. Tzeng and Chen (1993) proposed a multi-criteria SO TA model with an explicit pollution minimization criterion. The SO objective that affects decision-making is the sum of total travel time for road users, air pollution for non-users, and travel distance. The assumptions in this model are the same as those of the SO assignment in which a central controller can control and route traffic in such a way that the resultant traffic pattern is optimal from a system (or societal) perspective. Similarly, Nasiri et al. (2009) proposed an optimality assessment framework to assist freight transportation planning with environmental considerations, in which a multiple-objective optimization model with cost and environmental objectives is constructed. Zhang et al. (2010) proposed a cell-based assignment model to minimize the weighted sum of travel time and emissions.

Multiple objectives including environmental objectives have also been studied in the UE framework. Nagurney et al. (2002) considered multiple classes of travelers and each class is assumed to select route with the least weighted sum of travel time, travel cost, and emissions. The weights are not only class-dependent but also link-dependent. Jaber and O’Mahony (2009) further extended this model to include the value of time and travelers equipped with route guidance services.

Capturing environmental objectives in TA generally lead to non-convex objective functions in mathematical programming formulations, or non-monotone mappings in variational inequality formulations. Hence, using the classical algorithms such as the FrankWolfe algorithm (e.g., Tzeng and Chen, 1993; Rilett and Benedek, 1994; Benedek and Rilett, 1998), the method of successive averages (e.g., Rilett and Benedek, 1994; Benedek and Rilett, 1998), projection method (e.g., Nagurney et al., 2002) and the generalized reduced 
gradient algorithm (e.g., Jaber and O’Mahony, 2009) to solve the TA models cannot guarantee that the solution obtained is globally optimal. To address this issue, Sugawara and Niemeier (2002) modified the Frank-Wolfe algorithm by introducing Simulated Annealing for finding the step size. Zhang et al. (2010) further adopted genetic algorithm (GA) to solve for solutions. Still, very few solution methods were particularly developed for these models and tested for large-network applications.

\section{Models with environmental constraints}

Environmental constraints have been considered in three forms: Environmental capacity constraints, equity constraints, and marketable pollution permits.

Environmental capacity has been proposed by Buchanan (1963), and represents the maximum acceptable pollutant or noise level imposed by planners. To portray this concept in TA, an environmental capacity constraint is included in the formulation (e.g., Yang et al., 2005, 2010; Zhao and Gao, 2006; Feng et al., 2010; Chen et al., 2011b; Li et al., 2012; Zhong et al., 2011), which requires that total emissions or the noise from a link cannot exceed the corresponding environmental capacity.

Environmental equity proposed by Rilett and Benedek (1994) can also be captured in constraints. This concept is that traffic is routed through a given network by the system operators in such a way that vehicle emissions or noise levels on the adjacent streets do not exceed some maximum safety standard, for example for health reasons. This can be viewed as an extension of a capacitated UE assignment.

Marketable pollution permits have been examined in the framework of congested TA (Nagurney et al., 1998) in which a fixed number of permits of each link is issued by the government to allow drivers to buy the permits for emitting pollutants on that link at certain rate and the permit holders can sell their permits to others. This idea has been extended to 
consider path-based and OD-based permits (e.g., Nagurney, 2000a) and dynamic networks (e.g., Nagurney and Zhang, 2001).

The above environmental constraints are always nonlinear, leading to a non-convex solution set in general. Hence, solving TA models with environmental constraints is more difficult than those without. Heuristic methods (e.g., Ferrari, 1995) have been developed for these models formulated as constrained optimization models. Classical methods such as the inner penalty technique (e.g., Yang and Bell, 1997) and augmented Lagrangian multiplier technique (e.g., Yang et al., 2010) have also been used to solve these models. Recently, Chen et al. (2011b) developed a predictor-corrector decomposition algorithm to solve the variational inequality model. Xu et al. (2012) reformulated the constrained model as an unconstrained optimization model through a gap function and solved the resultant model based on a gradient-based solution algorithm with a self-regulated averaging stepsize scheme. However, all these approaches have not been tested for large-scale networks.

\section{Models for EIA}

Environmental impacts have been evaluated by TA models. For example, Nagurney (2000b) demonstrated the existence of emissions paradox using the classical TA framework. That is, the total emissions increase after adding the new link to the network. Nagurney and Dong (2001) further considered emissions paradox in a combined transportation and telecommunication networks. Szeto et al. (2008a) analyzed the conditions of the simultaneous occurrence of Braess' and emission paradoxes for Braess’ network. In addition, Szeto et al. (2008b) also discovered that providing better traffic information to travelers can result in higher overall emissions. Nagurney et al. (2010) proposed EIA indices to evaluate the environmental effects of link capacity degradation in transportation networks. 


\section{Bi-level transportation problems with environmental considerations}

The bi-level transportation problem with environmental considerations (BTPE) can be formulated as:

$$
\operatorname{Min}_{\mathbf{x}} f(\mathbf{x}, \mathbf{y})
$$

subject to

$$
\begin{aligned}
& \mathbf{x} \in \boldsymbol{\omega}, \\
& \underset{\mathbf{y}}{\operatorname{Min}} F(\mathbf{x}, \mathbf{y}) \\
& \mathbf{y} \in \mathbf{S}(\mathbf{x}),
\end{aligned}
$$

where $\mathbf{x} \in R^{n}$ and $\mathbf{y} \in R^{m}$ are the decision variables of the upper- and lower-level problems

respectively; $f\left[R^{n} \times R^{m} \rightarrow R\right]$ and $F\left[R^{n} \times R^{m} \rightarrow R\right]$ are the objective functions of the upper- and lower-level problems respectively; and $\boldsymbol{\omega} \subset R^{n}$ and $\mathbf{S}\left[R^{n} \Rightarrow R^{m}\right]$ are the solution sets of the upper- and lower-level problems respectively. Depending on the context, the upper-level problem often includes environmental impact measures such as fuel consumption or emissions in either the objective function or environmental constraints as indicated in Table 3. In some problems, the impact on the environment is portrayed by a toll charge. Moreover, the lower-level problem is a TA problem or its generalization. This implies that BTPE is a special type of general bi-level problems.

Similar to typical bi-level problems, BTPE can be viewed as a two-stage optimization problem or a leader-follower problem, in which the upper level is the leader's problem and the lower level is the follower's problem. The leader makes a decision taking the reaction of the follower into consideration, and the follower only makes his/her decision after the leader has made his/hers.

BTPE can also be reformulated as a mathematical program with equilibrium 
constraints (MPEC) by replacing the lower-level problem with its first-order optimality conditions and assuming that certain conditions of regularity hold. Mathematically, the MPEC can be formulated as:

$$
\underset{\mathbf{x}, \mathbf{y}}{\operatorname{Min}} f(\mathbf{x}, \mathbf{y})
$$

subject to

$$
\begin{aligned}
& \mathbf{x} \in \boldsymbol{\omega}, \\
& \left(\mathbf{y}-\mathbf{y}^{*}\right)^{\mathrm{T}} \mathbf{H}\left(\mathbf{y}^{*}\right) \geq 0, \forall \mathbf{y} \in \mathbf{S}(\mathbf{x}),
\end{aligned}
$$

where $\mathbf{y}^{*} \in R^{m}$ is an optimal solution of the equilibrium problem in the form of a variational inequality given $\mathbf{x}$; and $\mathbf{H}(.) \in R^{m}$ is the vector function of $\mathbf{y}$ in the variational inequality.

Table 3 also presents different applications of BTPE, including the road network expansion problem (RNEP), the toll design problem (TDP), the combined signal control and assignment problem (CSCAP), the ramp metering problem (RMP), the car ownership control problem (COCP) and combinations thereof. RNEP is concerned with the addition of new highways to the existing highway system or widening existing highways taking into account traveler behavior. TDP is to determine the optimal toll level on each link of the road network if the link is allowed to charge a toll. CSCAP is to determine the optimal traffic signal timing in a road network while considering the route choice behavior of travelers. RMP is to determine traffic signal timing to control the number of vehicles entering freeways in order to improve their performance. In some cases, the performance of the surface streets is also taken into account. COCP is to determine an optimal car ownership in each zone of the study. Currently, CP mainly focuses on either the combined signal control and road network expansion problem, (e.g., Cantarella and Vitetta, 2006; Zhang et al., 2006; Zhao and Gao, 2006; Huang et al., 2010) or the combined network expansion and tolling problem (e.g., 
Dimitriou et al., 2009).

According to Table 3, to date, only a few studies are related to BTPE especially CSCAP, COCP, and RMP with ES consideration. Moreover, these studies mainly focus on emissions and very few focuses on other dimensions of ES such as noise, environmental justice, and environmental pollution, where environmental justice can be considered as an extension of equity with a focus on minority and low income population but it includes social and economic effects in addition to environmental effects. When ES is captured in the objective function, it is always considered in form of either total network emissions or emission costs. The environmental objective is often combined with other objectives using the weighted sum approach, but it is sometimes treated as the only objective in the model or one of the objectives in the multi-criteria optimization model to find the Pareto front. When ES is captured in the constraint, it is always in form of environmental capacity constraint (to restrict link flow not to be greater than environmental capacity), link emission constraint (to restrict link emissions not to exceed the acceptable value), and equilibrium constraints with the emission tolls involved. The latter is derived from problems with the total network emission constraint (to restrict the total emissions in the network).

The solution methods mainly relied on heuristics such as sensitivity analysis-based heuristics or meta-heuristics such as GA or Particle Swarm Optimization (PSO) without considering the mathematical properties of their problem. Furthermore, only Zhao and Gao (2006) has attempted to develop exact global optimization methods to solve the combined signal control and road network expansion problem.

\section{Future research directions}

The following research directions are proposed and can generally be classified into theories, modeling approaches, algorithms, analyses, and applications. 


\section{Theories}

Extensions of the BRUE to consider travel time reliability

BRUE can be extended to include reliability in terms of travel time, which can be used to consider the trade-off between travel time and the penalty for being late due to unpredictability. Boundedly rational reliability-based UE can be defined using the concept of a travel time budget or mean excess travel time. This new concept, which fills a gap in the literature, can be applied to the evaluation of ES and transport network design.

\section{Extensions of environmental equities to consider its dimensionally distributive effects}

Environmental equity can be extended to consider its horizontal and vertical dimensions which are analogous in their definitions to those of horizontal and vertical equities that are applied in transportation (e.g., Litman, 2002). Horizontal environmental equity is concerned with the equal distribution of negative environmental impact within the same group or class of people who have the same abilities and needs, such as social class, value of time or income. The environmental equity proposed in Rilett and Benedek (1994) is indeed an example of this, which considered equity in terms of emissions during the same period. However, it can also include the impact of noise, and take into consideration the distributional effects across different periods similar to the equity in Szeto and Lo (2006b). This horizontal environmental equity across different periods is said to be achieved if the differences in total environmental impact measures (such as emission or noise levels) between two consecutive periods are acceptable.

Vertical environmental equity is concerned with the equal distribution of negative environmental impact between various groups or classes of people. This equity is said to be achieved if the absolute difference in the environmental impact measure between each class 
is acceptable and no social or income class experiences a considerably larger environmental impact.

\section{Modeling approaches}

Modeling pollutant concentrations due to vehicle emissions

Much research was focused on the estimation of vehicle emissions but very few (e.g., Wang et al., 2009) has attempted to go further to estimate the changes in pollutant concentration levels due to traffic emissions. However, a complete EIA should comprise estimating emissions and ambient pollutant concentration. It is therefore important to pay more attention to developing methodologies to estimate the concentration. One future direction can be extending the model of Wang et al. (2009) to consider the speed profiles in the concentration estimation.

Developing noise prediction models based on mesoscopic traffic model outputs

Existing dynamic noise prediction models mainly rely on the traffic flow output from either macroscopic or microscopic traffic flow models. Microscopic traffic flow models can include detailed vehicle dynamics, such as the acceleration and deceleration of vehicles, which are suitable for some traffic noise prediction applications, including noise from signalized intersections and roundabouts. However, these models are the most computationally demanding and require a large amount of data for calibration and validation. Thus, they are normally used for small- to medium-scale study areas. Macroscopic models are the most computationally efficient and can produce good results (Can et al., 2008) in some situations, but they may not be accurate for detailed noise modeling at signalized intersections or roundabouts. Mesoscopic modeling seems to strike a balance between including a sufficient level of detailed vehicle dynamics and meeting the computational 
requirements for large-scale study applications, and can be extended for dynamic traffic noise prediction. Further work is needed on developing noise prediction models based on mesoscopic traffic model outputs.

Developing a multi-objective optimization framework with emissions and noise considerations

Previous studies of BTPE mainly focused on the aspect of either emissions or noise. However, bi-level models with a single objective could generate designs which may mitigate congestion problems but exacerbate environmental problems, for example, through increased vehicle emissions and noise. Such designs can cause paradoxical situations (e.g., Szeto et al., 2008). A compromised design using a multi-objective optimization framework is needed to cope with congestion and environment problems simultaneously. Szeto et al. (2009b) proposed such a framework through the hybrid approach in which the multiple objectives did not focus on ES, more specifically both vehicle emissions and noise. One potential research direction would be to extend this framework to incorporate both aspects.

A stochastic or reliability approach to incorporating environmental concerns into bi-level models

Most of the bi-level models that involve environmental considerations, as depicted in the fifth section, are deterministic models in which there are no uncertainties of model inputs and the input values are fixed and known. However, the inputs can be the output of other models that may be inaccurate. For example, the forecast of demand in 10 years' time may not be very accurate but for transport network improvement planning, it normally takes such long-term considerations into account. Therefore, it is necessary to extend these bi-level models to consider uncertainties. Incorporating recent stochastic modeling approaches (see Chen et al., 2011c) into these models is definitely one possible research direction. Moreover, 
one can define and incorporate reliability measures to evaluate environmental impacts in the upper-level objective functions or constraints, and adopt the reliability-based extension of Wardrop's principles in the lower-level problem, so that a new and more realistic reliabilitybased framework for ES can be developed.

A multi-dimensional, multi-criteria approach to incorporating economic, social, and environmental concerns into transport network modeling

Transportation networks are large-scale in nature and transportation is always associated with economic, social, and environmental issues that are faced by public and local authorities simultaneously. Therefore, it is important to develop appropriate transport network models to address these issues. For this purpose, one direction is to extend the model of Szeto et al. (2009b) to include indicators of the three dimensions of sustainability. In addition, the multiple-criteria model proposed by Jaber and O’Mahony (2009) can be used in the lower-level of the extended model.

\section{Algorithms}

Developing efficient, convergent, and robust algorithms for TA with environmental considerations for large-scale network applications

The environmental considerations result in nonlinear and non-convex constraint sets, non-convex objective functions in mathematical programming formulations, or nonmonotone mappings in variational inequality formulations, leading to the resultant models more difficult to solve for global optimality than classical TA models. Moreover, existing solution algorithms for TA with environmental considerations have only been applied to small and medium-sized networks. The robustness of the algorithms has also not been tested. As such, developing efficient, convergent and robust algorithms for solving the TA models with environmental considerations for large-scale network applications may consider as an 
important and challenging future research direction.

Development of tailored meta-heuristics to solve proposed or existing non-linear, non-convex bi-level transport problems

The proposed and existing models for BTPE with ES are non-convex and non-linear due to equilibrium constraints. In addition, when integer decision variables are involved, the resultant problems are non-deterministic polynomial-time-hard. It is therefore difficult to find a solution for exact global optima for realistic applications purely using exact methods, such as the branch-and-bound method. The development of meta-heuristics that consider the special structures of the models may be another potential future research direction. For example, repairing procedures can be developed to handle environmental equity constraints and ensure solution feasibility.

Improvement of the speed and quality of solution of meta-heuristics by incorporating sensitivity analysis-based heuristics or mathematical programming techniques

To reduce computation time, sensitivity analysis-based heuristics for handling equilibrium constraints can be developed and incorporated into meta-heuristics. The metaheuristics can also be combined with mathematical programming techniques, such as the successive quadratic programming method, to reduce computation time further. To improve the quality of the solution, the $\alpha$ branch-and-bound technique can be employed where the upper bound is obtained by the proposed meta-heuristics. For this purpose, the work conducted in Lo and Szeto (2002a,b), Szeto et al. (2006), Szeto and Wu (2011), and Miandoabchi et al. (2011) can be used as a starting point.

\section{Analyses}

The impact of various route choice behaviors on vehicle emissions and noise under different 
transportation and financing strategies

As shown in the fifth section, most of previous studies have focused on the impact of transportation strategies on vehicle emissions only. The impact on vehicle noise is seldom mentioned. In addition, traditional equilibrium principles such as Wardrop's are used to describe the route choice behavior of travelers in these evaluations. More realistic route choice behavior principles, such as the reliability-based, boundedly rational, and robust principles, have not been applied to the evaluation of the effectiveness of transportation strategies on emission and noise reduction. It would be interesting and meaningful to analyze and compare the impact of various route choice behaviors on vehicle emissions and noise under different transportation management strategies such as road pricing and route guidance. It will also be essential to evaluate the impact of proposed extensions of the BRUE route choice behavior on vehicle emissions and noise under different transportation infrastructure financing schemes such as build-operate-transfer and cost recovery schemes. All of the results based on more realistic route choice behavior principles can be compared with those based on traditional Wardrop’s principles, which will provide useful insights for transportation network planners and policy makers, for example, in terms of the importance of including the risk-aversive behavior of drivers into the analysis. All of these analyses are worthy of consideration in the future.

Deriving and analyzing speed-dependent second best tolls with simultaneous consideration of costs of emission and noise

Deriving speed-dependent marginal tolls with the consideration of the cost implication of emissions and noises to drivers in transportation networks is not novel (Guo and Hsu, 2010). However, these tolls are first-best and may not be practical because not all roads can be tolled in reality. Hence, it is important to derive second-best tolls for practical reasons. In addition, using the analytical, speed-dependent, best-second toll relationship, it 
will then be possible to analyze the effect of speed on the second-best tolling strategies, and compare this with the corresponding first-best toll and marginal congestion cost tolling in terms of charging locations and magnitude. New insights are expected from this analysis.

Horizontal and vertical environmental equities under different transportation strategies

Under different transportation strategies, one or more environmental inequities are possible. It is therefore important to analyze the environmental impact of the implementation of transportation strategies on people over time, space and social classes. The multi-objective model proposed in Szeto et al. (2009b) can be used for this purpose. This model can be combined with that in Szeto and Lo (2006b) to help determine the most equitable strategy. Definitely, other frameworks can be derived for this analysis in the future.

\section{Applications}

\section{Traveler information provision}

The bi-level programming approach has been applied to the analyses of traveler information provision (e.g. Szeto, 2007). In these analyses, travelers who use information provision services or who are equipped with route guidance services are usually assumed to possess better traffic information than unequipped travelers. The lower-level problem is normally formulated as a multi-class TA problem. Nevertheless, these analyses do not take into account the impact of traveler information provision on ES. Providing too much traffic information may result in more overall emissions and noise or a more uneven distribution of the environmental impact. Therefore, ES could be incorporated into these analyses in future research. 


\section{On-ramp metering}

According to Table 3, only one study related to ramp metering considered emissions. This problem is based on the static approach and the UE principle is adopted to depict the lower-level problem. Recent developments on dynamic ramp metering (e.g., Zhang et al., 2001; Meng and Khoo, 2010) can be used to determine more realistic time-varying metering rates and include the effect of emissions and noise in the model.

\section{Car ownership control}

To date, two studies have used this application to consider emissions (Table 3). Further work is needed on this application with regard to the consideration of noise. Moreover, other advanced route choice models depicted in the second section can be used to replace the UE model and new solution methods based on meta-heuristics can be used together with sensitivity analysis-based heuristics to improve the quality of the solution.

Combined signal control and assignment problem and its extension

Currently, only one study has been carried out on the combined signal control and assignment problem with the consideration of emissions, and four studies have dealt with combined signal control and network design problems (see Table 3). Further studies could extend the existing frameworks, which rely on a link performance function that cannot taken into account the stochastic nature of driver behavior, day-to-day variability in traffic demand, or traffic dynamics such as queue spillback, which greatly affect the spatial dispersion of emissions. These frameworks can be improved by using microscopic traffic simulation models. For example, Park et al. (2009) presented a sustainable traffic signal control and speed management framework which includes a microscopic traffic simulation model, a microscopic fuel consumption and emission model, and a GA-based optimizer. The 
framework was formulated into a stochastic optimization problem in which total emissions can be used as an objective function. The advantage of encapsulating the microscopic traffic simulation model and the microscopic fuel consumption and emission model is that the emission estimation is more accurate. However, traveler's route choice behavior is not taken into account. Another future research direction could be to incorporate the UE problem into the framework, and a further research direction could be to incorporate noise consideration. A third direction would be to incorporate the variance estimation technique discussed in Park et al. (2007) to estimate the variability of emissions and noise.

\section{Acknowledgements}

This research was jointly supported by a grant (200902172003) from the Hui Oi Chow Trust Fund, grants (201011159026, 201007176059) from the University Research Committee, HKU SPACE Research Fund and Faculty of Engineering Top-up Grant, and an Outstanding Researcher Award from the University of Hong Kong. The authors are grateful to the constructive comments of the four reviewers.

\section{References}

Aashtiani, H. (1979) The Multi-Modal Traffic Assignment Problem, PhD Thesis, Operations Research Center, MIT, Cambridge, MA.

Abdulhai, B. and Kattan, L. (2004) Traffic engineering analysis, chapter 6, in M. Kutz (Ed.) Handbook of Transportation Engineering, pp. 6.1-6.72 (USA: McGraw-Hill Publishing).

AGO (2003) Australian Methodology for the Estimation of Greenhouse Gas Emissions and Sinks 2003 - Energy (Transport) (Canberra: Australian Greenhouse Office).

Ahn, K. and Rakha, H. (2008) The effects of route choice decisions on vehicle energy consumption and emissions. Transportation Research Part D, 13, pp.151-167.

Anon. (1952) Handbook of Acoustic Noise Control, WADC Technical Report, 52-204 (Ohio: Wright Air Development Center).

Asmuth, R. (1978) Traffic Network Equilibria, PhD Thesis, Department of Operations Research, Stanford University, Stanford, CA.

Beckmann, M. (1952) A continuous model of transportation, Econometrica, 20, pp. 643-660. 
Beckmann, M.J., Mcguire, C.B. and Winsten, C.B. (1956) Studies in the Economics of Transportation. Yale University Press, New Haven, Conn.

Benedek, C.M. and Rilett, L.R. (1998) Equitable traffic assignment with environmental cost function. Journal of Transportation Engineering, 124, pp.16-22.

Benson, P.E. (1989) CALINE4 - A Dispersion Model for Predicting Air Pollutant Concentrations near Roadways, FHWA/CA/TL-84/15 (Revised) (Sacramento: California Department of Transportation).

Bhaskar, A., Chung, E. and Kuwahara, M. (2007) Development and implementation of the areawide Dynamic ROad traffic NoisE (DRONE) simulator. Transportation Research Part D, 12, pp. 371-378.

Boulter, P.G., McCrae, I.S. and Barlow, T.J. (2007) A Review of Instantaneous Emission Models for Road Vehicles, Project Report PPR 267 (Berkshire: Transport Research Laboratory).

Buchanan, C. (1963) Traffic in Town, Report of the Steering Group and Working Group Appointed by the Minister of Transport, London.

Burgess, M.A. (1977) Noise prediction for urban traffic conditions - related to measurement in Sydney metropolitan area. Applied Acoustics, 10, pp. 1-7.

Can, A., Chevallier, E., Nadji, M. and Leclercq, L. (2010) Dynamic traffic modeling for noise impact assessment of traffic strategies. Acta Acustica united with Acustica, 96, pp. 482-493.

Can, A., Leclercq, L. and Lelong, J. (2008) Dynamic estimation of urban traffic noise: Influence of traffic and noise source representations. Applied Acoustics, 69, pp. 858867.

Cantarella, G.E. and Vitetta, A. (2006) The multi-criteria road network design problem in an urban area. Transportation, 33, pp. 567-588.

Cappiello, A. (2002) Modelling Traffic Flow Emissions, MSc Thesis (Cambridge: Massachusetts Institute of Technology).

CARB (California Air Resources Board) (2010) Retrieved from: http://arb.ca.gov/msei/onroad/latest_version.htm.

Centre Scientifique et Technique du Batiment (1991) Etude théorique et expérimentale de la propagation acoustique, Revue d'Acoustique n.70 (in French).

Chan, K.S. and Lam, W.H.K. (2005) Impact of road pricing on road network reliability. Journal of Eastern Asia Society for Transportation Studies, 6, pp. 2060-2075. 
Chen, A. and Xu, X. (2012) Goal programming approach to solving the network design problem with multiple objectives and demand uncertainty. Expert Systems with Applications, 39, pp. 4160-4170.

Chen, A. and Zhou, Z. (2010) The $\alpha$-reliable mean-excess traffic equilibrium model with stochastic travel times. Transportation Research Part B, 44, pp. 493-513.

Chen, A., Zhou, Z. and Lam, W.H.K. (2011a) Modeling stochastic perception error in the mean-excess traffic equilibrium model with stochastic travel times. Transportation Research Part B, 45, pp. 1619-1640.

Chen, A., Zhou, Z. and Ryu, S. (2011b) Modeling physical and environmental side constraints in traffic equilibrium problem. International Journal of Sustainable Transportation, 5, pp. 172-197.

Chen, A., Zhou, Z., Chootinan, P., Ryu, S., Yang, C., Wong, S.C. (2011c) Transport network design problem under uncertainty: A review and new developments. Transport Reviews, 31, pp. 743-768.

Chevallier, E., Can, A., Nadji, M. and Leclercq, L. (2009) Improving noise assessment at intersections by modeling traffic dynamics. Transportation Research Part D, 14, pp. 100-110.

Chiou, Y.C. and Chen, T.C. (2010) Direct and indirect factors affecting emissions of cars and motorcycles in Taiwan. Transportmetrica, 6, pp. 215-233.

Cocchi, A., Farina, A. and Lopes, G. (1991) Modelli matematici per la previsione del rumore stradale: verifica ed affinazione del modello CNR in base a rilievi sperimentali nella città di Bologna, Acta of 19 Convegno Nazionale AIA (April 10-12 1991 Naples Italy) (in Italian).

Cvetković, D., Praščević, M. and Stojanović, V. (1997) NAISS - Model for traffic noise prediction. The Scientific Journal FACTA UNIVERSITATIS, Series: Working and Living Environmental Protection, 1, pp. 73-81.

Daganzo, C.F. and Sheffi, Y. (1977) On stochastic models of traffic assignment. Transportation Science, 11, pp. 253-274.

De Coensel, B., De Muer, T., Yperman, I. and Botteldoren, D. (2005) The influence of traffic flow dynamics on urban soundscape. Applied Acoustics, 66, pp. 175-194.

Department of Transport (DOT) (1988) Calculation of Road Traffic Noise (London: HMSO). Dimitriou, L., Kaltsounis, A. and Stathopoulos, A. (2009) Introducing transportation-related carbon footprint considerations in optimal urban road infrastructure management. International Journal of Energy and Environment, 3, pp. 103-111. 
Duthie, J. and Waller, S.T. (2008) Incorporating environmental justice measures into equilibrium-based network design. Transportation Research Record, 2089, pp. 58-65.

Dutilleux, G., Defrance, J., Gauvreau, B. and Besnard, F. (2008) The revision of the French method for road traffic noise prediction. Journal of the Acoustical Society of America, 123, pp. 3150-3150.

EC (European Commission) (1995) ESTEEM - European Scenarios on Transport-EnergyEnvironment for Metropolitan Areas, Final Report (Brussels: The European Commission)

EEA (European Environment Agency) (2012) COPERT 4 Computer programme to calculate emissions from road transport - User manual version 9. Retrieved from http://www.emisia.com/documentation.html

EMPA (1987) Modèle de Calcul de Bruit du Trafic Routier Pour Ordinateur, 1ère partie: Manuel d'utilisation du logiciel STL-86 version l.0 (Berne: L'Office fédéral de la Protection de l'Environnement) (in French).

Fagotti, C. and Poggi, A. (1995) Traffic noise abatement strategies, the analysis of real case not really effective, in Proceedings of 18th International Congress for Noise Abatement (September 11-13, 1995 Bologna Italy), pp. 223-233.

Federal Highway Administration (FHWA) (2011) Traffic Noise Model. Retrieved from http://www.fhwa.dot.gov/environment/noise/traffic_noise_model/

Feng, T., Zhang, J., Fujiwara, A. and Timmermans, H.J.P. (2010) An integrated model system and policy evaluation tool for maximizing mobility under environmental capacity constraints: a case study in Dalian City, China. Transportation Research Part D, 15, pp. 263-274.

Ferguson, E.M., Duthie, J. and Waller, S.T. (2010) Network Methods for Project Selection based on Optimizing Environmental Impact, Research Report SWUTC/10/161026-1 (Austin: University of Texas at Austin).

Ferrari, P. (1995) Road pricing and network equilibrium. Transportation Research Part B, 29(5), pp. 357-372.

Fomunung, I., Washington, S. and Guensler, R. (1999) A statistical model for estimating oxides of nitrogen emissions from light-duty motor vehicles. Transportation Research Part D, 4, pp. 333-352.

Galloway, W.J., Clark, W.E. and Kerrick, J.S. (1969) Urban highway noise: measurement, simulation, and mixed reactions, NCHRP Report 78 (Washington, DC: Highway Research Board). 
Guo, S.P. and Hsu, C.I. (2010) Impacts of transportation external cost pricing and transit fare reductions on household mode/route choices and environmental improvements. Journal of Urban Planning and Development, 136, pp. 339-348.

Hall, R.W. (1993) Travel outcome and performance: the effect of uncertainty on accessibility. Transportation Research Part B, 17, pp. 275-290.

Hickman, J., Hassel, D., Joumard, R., Samaras, Z. and Sorenson, S. (1999) MEET Methodology for Calculating Transport Emissions and Energy Consumption, Project Report SE/491/98 (Berkshire: Transport Research Laboratory).

Hızır, A.E. (2006) Using Emission Functions in Mathematical Programming Models for Sustainable Urban Transportation: an Application in Bilevel Optimization, MSc Thesis (Istanbul: Sabanci University).

HKSAR Environmental Protection Department (2007) Retrieved from http://www.epd.gov.hk/epd/english/environmentinhk/air/data/emission_inve.html

Huang, K., Zhang, J., He, M. and Liao, W. (2010) An optimal model and solution algorithm of urban traffic network considering exhaust emission control, in Proceedings of the 2010 International Conference of Logistics Engineering and Management (October 810, 2010 Chengdu China), pp. 528-534.

Huang, K., Zhang, J., He, M. and Zhu, J. (2009) Bi-level programming model of urban traffic network considering noise pollution control, in Proceedings of the 2nd International Conference on Transportation Engineering (July 25-27, 2009 Chengdu China), pp. 3399-3404.

IPCC (1996) Revised 1996 IPCC guidelines for national greenhouse gas inventories. - Paris: OECD, in J.T. Houghton, L.G. Meira Filho, B. Lim, K. Tréanton, I. Mamaty, Y. Bonduki, D.J. Griggs and B.A. Callender. (Eds.) Reference Manual (Volume 3). IVE (International Vehicle Emissions) (2011) Retrieved from http://www.issrc.org/ive/ Jaber, X.Q. (2009) Analytical Approaches to Evaluating Sustainable Transportation Strategies, PhD Thesis (Dublin: Trinity College Dublin).

Jaber, X.Q. and O'Mahony, M. (2009) Mixed stochastic user equilibrium behavior under traveler information provision services with heterogeneous multiclass, multicriteria decision making. Journal of Intelligent Transportation Systems, 13, pp. 188-198.

Jakkula, N. and Asakura, Y. (2009) Accuracy of optimum road pricing considering local emissions of road traffic network, in Proceedings of the 12th IFAC (International Federation of Automatic Control) Symposium on Control in Transportation Systems (September 2-4, 2009, Redondo Beach, California). 
Jia, P., Kato, H. and Hayashi, Y. (2009) Road network optimization model with consideration of dynamic changes in long term evaluation for developing cities, in Proceedings of the 88th Transportation Research Board Annual Meeting.

Jiang, Y.Q., Wong, S.C., Ho, H.W., Zhang, P., Liu, R. and Sumalee, A. (2011) A dynamic traffic assignment model for a continuum transportation system. Transportation Research Part B, 45, pp. 343-363.

Johnson, D.R. and Saunders, E.G. (1968) The evaluation of noise from freely flowing road traffic. Journal of Sound and Vibrations, 7, pp. 287-309.

Josse, R. (1972) Notions d'Acoustique (Paris: Ed. Eyrolles) (in French).

Joumard, R., Jost, P., Hickman, J. and Hassel, D. (1995b) Hot passenger car emissions modeling as a function of instantaneous speed and acceleration. Science of the Total Environment, 169, pp. 167-174.

Kim, B.J. and Kim, W. (2006) An equilibrium network design model with a social cost function for multimodal networks. Annual on Regional Science, 40, pp. 473-491.

Kunselman, P., McAdams, H.T., Domke, C.J. and Williams, M.E. (1974) Automobile exhaust emission modal analysis model, in EPA 460/3-74-005 (Ann Arbor: EPA Office of Mobil Source Air Pollution Control).

Lam, W.H.K., Chan, K.S., Li, Z. and Bell, M.G.H. (2010) A risk-averse user equilibrium model for route choice problem in signal-controlled networks. Journal of Advanced Transportation, 44, pp. 219-230.

Lamure, C. (1965) Niveaux de bruit au voisinage des autoroutes (Noise levels in the vicinity of highways), in Proceedings of the Fifth International Congress on Acoustics (1965 Liege Belgium) (in French).

Leclercq, L. and Lelong, J. (2001) Dynamic evaluation of urban traffic noise, in A. Alippi (Ed.) Proceedings of the 17th International Congress on Acoustics (Rome).

Lelong, J. and Leclercq, L. (2003) Dynamic evaluation of the noise emitted by a bimodal (passenger cars/buses) traffic flow, in Proceedings of the 32nd International Congress and Exposition on Noise Control Engineering, Jeju International Convention Center (August 25-28, 2003 Seogwipo Korea).

Li, X.Q., Szeto, W.Y. and O'Mahony, M. (2007) Incorporating land use, transport and environmental considerations into time-dependent tolling strategies. Journal of Eastern Asia Society for Transportation Studies, 7, pp. 360-375.

Li, Z.C., Lam, W.H.K., Wong, S.C. and Sumalee, A. (2012) Environmentally sustainable toll design for congested road networks with uncertain demand. International Journal of 
Sustainable Transportation, 6, pp. 127-155.

Litman, T. (2002) Evaluating transportation equity. World Transport Policy \& Practice, 8, pp. 50-65.

Lo, H.K. and Szeto, W.Y. (2002a) A cell-based variational inequality formulation of the dynamic user optimal assignment problem. Transportation Research Part B, 36, pp. 421-443.

Lo, H.K. and Szeto, W.Y. (2002b) A cell-based dynamic traffic assignment model: formulation and properties. Mathematical and Computer Modelling, 35, pp. 849-865.

Lo, H.K., Luo, X.W. and Siu, B.W.Y. (2006) Degradable transport network: travel time budget of travelers with heterogeneous risk aversion. Transportation Research Part B, 40, pp. 792-806.

Lv, Z.L., Fan, B.Q., Liu, J.J. and Zhou, Y.H. (2006) Bi-level multi-objective programming model for the ramp control and pollution control on urban expressway networks. Kongzhi yu Juece (Control and Decision), 21, pp. 64-67 (in Chinese).

Mahmassani, H.S. and Chang, G.L. (1987) On boundedly-rational user equilibrium in transportation systems. Transportation Science, 21, pp. 89-99.

Mathew, T.V. and Sharma, S. (2006) Continuous network design with emission pricing as a optimization problem, in K.C.P. Wang, B.L. Smith, D.R. Uzarski, S.C. Wong (Eds.) Proceedings of Applications of Advanced Technology in Transportation (August 1316, 2006 Chicago USA), pp. 804-809.

Matzoros, A. (1990) Results from a model of road traffic air pollution, featuring junction effects and vehicle operating modes. Traffic Engineering and Control, 30, pp. 24-37.

Meng, Q. and Khoo, H.L. (2010) A Pareto-optimization approach for a fair ramp metering. Transportation Research Part C, 18, pp. 489-506.

Miandoabchi, E., Farahani, R.Z. and Szeto, W.Y. (2011) Bi-objective bimodal urban road network design using hybrid metaheuristics. Central European Journal of Operations Research (in press), DOI: 10.1007/s10100-011-0189-4.

MITHRA, Retrieved from: http://www.sagetechnologies.com/principals/01db/pdf_documents/mithra.pdf

Nagurney, A. (1993) Network Economics: A Variational Inequality Approach (Massachusetts: Kluwer Academic Publishers).

Nagurney, A. (2000a) Alternative pollution permit systems for transportation networks based on origin/destination pairs and paths. Transportation Research Part D, 5, pp. 37-58.

Nagurney, A. (2000b) Congested urban transportation networks and emission paradoxes. 
Transportation Research Part D, 5, pp. 145-151.

Nagurney, A. (2000c) Sustainable Transportation Networks (Cheltenham: Edward Elgar Publishers).

Nagurney, A. and Dong, J. (2001) Paradoxes in networks with zero emission links: implications for telecommunications versus transportation. Transportation Research Part D, 6, pp. 283-296.

Nagurney, A. and Zhang, D. (2001) Dynamics of a transportation pollution permit system with stability analysis and computations. Transportation Research Part D, 6, pp. 243268.

Nagurney, A., Dong, J. and Mokhtarian, P.L. (2002) Traffic network equilibrium and the environment: a multicriteria decision-making perspective, in E. Kontoghiorges, B. Rustem, S. Siokos (Eds.) Computational Methods in Decision-Making, Economics and Finance (Dordrecht: Kluwer Academic Publishers).

Nagurney, A., Qiang, Q. and Nagurney, L.S. (2010) Environmental impact assessment of transportation networks with degradable links in an era of climate change. International Journal of Sustainable Transportation, 4, pp. 154-171.

Nagurney, A., Ramanujam, P., and Dhanda, K.K. (1998) Multimodal traffic network equilibrium model with emission pollution permits: compliance vs noncompliance. Transportation Research, Part D, 35, pp. 349-374.

Nasiri, F., Nanuilova, A. and Huang, G.H. (2009) Environmental policy analysis in freight transportation planning: an optimality assessment approach. International Journal of Sustainable Transportation, 3, pp. 88-109.

Nickson, A. F. (1965) Can community reaction to increased traffic noise be forecast? In Proceedings of the Fifth International Congress on Acoustics.

NRC (National Research Council) (2000) Modeling Mobile Source Emissions (Washington, D.C.: National Academy Press).

Park, B.B. and Kamarajugadda, A. (2007) Development and evaluation of a stochastic traffic signal optimization method. The International Journal of Sustainable Transportation, 1, pp. 193-207.

Park, B.B., Yun, I. and Ahn, K. (2009) Stochastic optimization for sustainable traffic signal control. International Journal of Sustainable Transportation, 3, pp. 263-284.

Qiu, Y. and Chen, S. (2007) Bi-level programming for continuous network design of comprehensive transportation system based on external optimization, in Proceedings of 2007 IEEE International Conference on Grey Systems and Intelligent Services, 
GSIS 2007, (November 18 - 20, 2007 Nanjing China), pp. 1186-1190.

Quartieri, J., Mastorakis, N. E., Iannone, G., Guarnaccia, C., D’Ambrosio, S., Troisi, A. and Lenza, T.L.L. (2009) A review of traffic noise predictive models, in Proceedings of the 5th WSEAS International Conference on Applied and Theoretical Mechanics (December 14-16, 2009 Puerto De La Cruz Canary Islands Spain).

Rilett, L.R. and Benedek, C.M. (1994) Traffic assignment under environmental and equity objective. Transportation Research Record, 1443, pp. 92-99.

RLS (1990) Richtlinien für den Lärmschutz an Strassen, BM für Verkehr, Bonn (in German).

Scora, G. and Barth, M. (2006) Comprehensive Modal Emissions Model (CMEM), Version 3.01. User' s Guide. Retrieved from http://www.cert.ucr.edu/cmem/docs/CMEM_User_Guide_v3.01d.pdf

Shao, H., Lam, W.H.K. and Tam, M.L. (2006) A reliability-based stochastic traffic assignment model for network with multiple user classes under uncertainty in demand. Networks and Spatial Economics, 6, pp. 173-204.

Sharma, S. and Mishra, S. (2011) Optimal emission pricing models for containing carbon footprints due to vehicular pollution in a city network, in Proceedings of the 90th Transportation Research Board Annual Meeting.

Simon, H.A. (1955) A behavioral model of rational choice. Quarterly Journal of Economics, 69, pp. 99-118.

Simon, H.A. (1997) Models of Bounded Rationality (Vol. 3) (Cambridge: The MIT Press).

Smit, R. (2006) An Examination of Congestion in Road Traffic Emission Models and Their Application to Urban Road Networks, PhD Thesis (Australia: Griffith University).

Smit, R., Ntziachristos, L. and Boulter, P. (2010) Validation of road vehicle and traffic emission models: a review and meta-analysis. Atmospheric Environment, 44, pp. 2943-2953.

Smith, M.J. (1979) The existence, uniqueness and stability of traffic equilibrium. Transportation Research Part B, 13, pp. 295-304.

Stead, D. (2008) Transport policies: actions, intentions and perceived effectiveness, in: A. Perrels, V. Himanen, M. Lee-Gosselin (Eds.) Building Blocks for Sustainable Transport: Obstacles, Trends Solutions (London: Emerald).

Steele, C. (2001) A critical review of some traffic noise prediction model. Applied Acoustics, 62, pp. 271-287.

Sugawara, S. and Niemeier, D.A. (2002) How much can vehicle emissions be reduced? 
Exploratory analysis of an upper boundary using an emissions-optimized trip assignment. Transportation Research Record, 1815, pp.29-37.

Sutton, P. (2004) A Perspective on Environmental Sustainability. Retrieved from http://www.ces.vic.gov.au/ces/wcmn301.nsf/obj/cesplan/\$file/A+Perspective+on+env ironmental+sustainability.pdf

Szeto W.Y. (2007) Competition between information service providers and toll road operators: modeling frameworks. Journal of Intelligent Transportation Systems, 11, pp. 41-56.

Szeto, W.Y. (2011) Cooperative game approaches to measuring network reliability considering paradoxes. Transportation Research Part C, 11, pp. 229-241.

Szeto, W.Y. and Lo, H.K. (2006a) Dynamic traffic assignment: properties and extensions. Transportmetrica, 2, pp. 31-52.

Szeto, W.Y. and Lo, H.K. (2006b) Transportation network improvement and tolling strategies: The issue of intergeneration equity. Transportation Research Part A, 40, pp. 227-243.

Szeto, W.Y. and Wong, S.C. (2011) Dynamic traffic assignment: model classifications and recent advances in travel choice principles. Central European Journal of Engineering, 2, pp. 1-18.

Szeto, W.Y. and Wu, Y. (2011) A simultaneous bus route design and frequency setting problem for Tin Shui Wai, Hong Kong. European Journal of Operational Research, 209, pp. 141-155.

Szeto, W.Y., Jaber X.Q. and O'Mahony, M. (2008a) Simultaneous occurrence of braess' and emission paradoxes, in Proceedings of the Sixth International Conference on Traffic and Transportation Studies (August 5-7, 2008 Nanning, China), pp. 625-634.

Szeto, W.Y., Jaber X.Q. and O'Mahony, M. (2008b). Paradoxes with the traveler information provision services, in Proceedings of the Ninth Intelligent Transport Systems AsiaPacific Forum \& Exhibition (July 14-16, 2008 Singapore), CD-ROM.

Szeto, W.Y., Jaber, X.Q. and O'Mahony, M. (2009b) Time-dependent discrete network design frameworks considering land use. Computer Aided Civil and Infrastructure Engineering, 25, pp. 411-426.

Szeto, W.Y., Jiang, Y. and Sumalee, A. (2011) A cell-based model for multi-class doubly stochastic dynamic traffic assignment. Computer Aided Civil and Infrastructure Engineering, 26, pp. 595-611.

Szeto, W.Y., O’Brien, L. and O’Mahony, M. (2006) Risk-averse traffic assignment with 
elastic demand: NCP formulation and solution method for assessing performance reliability. Networks and Spatial Economics, 6, pp. 313-332.

Szeto, W.Y., O’Brien, L. and O'Mahony, M. (2009a) Measuring network reliability by considering paradoxes: the multiple network demon approach. Transportation Research Record, 2090, pp. 42-50.

TNO (2001) Emissions and congestion - estimation of emissions on road sections and the Dutch motorway network, in N.L.J. Gense, I.R. Wilmink, H.C. Van de Burgwal (Eds.) Report No. 01.OR.VM.0441/NG (The Netherlands: TNO Automotive).

Tsukui, K., Oshino, Y., van Blokland, G. and Tachibana, H. (2010) Study of the road traffic noise prediction method applicable to low-noise road surfaces. Acoustical Science and Technology, 31, pp. 102-112.

Tzeng, G.H. and Chen, C.H. (1993) Multiobjective decision making for traffic assignment. IEEE Transactions on Engineering Management, 40, pp. 180-187.

US EPA (United Stated Environmental Protection Agency) (1997) Development of speed correction cycles, in T.R. Carlson, T.C. Austin (Eds.) Sierra Research, Report No. M6.SPD.001 (Washington, DC: US Environmental Protection Agency).

US EPA (2010) Retrieved from http://www.epa.gov/otaq/models/moves/index.htm Vickrey, W.S. (1969) Congestion theory and transport investment. American Economics Review, 59, pp. 251-261.

Voet, E. van der, Guinée, J.B. and Udo de Haes, H.A, (Eds.). (2000) Heavy Metals: A Problem Solved? Methods and Models to Evaluate Policy Strategies for Heavy Metals. Environment \& Policy, 22 (Dordrecht: Kluwer Academic Publishers).

Wang, G., Bai, S. and Ogden, J.M. (2009) Identifying contributions of on-road motor vehicles to urban air pollution using travel demand model data. Transportation Research Part D, 14, pp. 168-179.

Wardrop, J. (1952) Some theoretical aspects of road traffic research. ICE Proceedings: Part II, Engineering Divisions, 1, pp. 325-362.

Wismans, L., van Berkum, E. and Bliemer, M. (2011) Modelling externalities using dynamic traffic assignment models: a review. Transport Reviews, 31, pp. 521-545.

Xu, X., Chen, A. and Cheng, L. (2012) Reformulating environmentally constrained traffic equilibrium via a smooth gap function. International Journal of Sustainable Transportation, submitted.

Yamamoto, K. (2010) Road traffic noise prediction model “'ASJ RTN-Model 2008’’, Report of the Research Committee on Road Traffic Noise. Acoustical Science and 
Technology, 31, pp. 1.

Yang, H. and Bell, M.G.H. (1997) Traffic restraint, road pricing and network equilibrium. Transportation Research Part B, 31, pp. 303-314.

Yang, H., Xu, W., He, B. and Meng, Q. (2010) Road pricing for congestion control with unknown demand and cost functions. Transportation Research Part C, 18, pp. 157175.

Yang, Z., Jia, P. and Feng, T. (2005) Maximizing car ownership under constraints of environment sustainability in a city. Journal of the Eastern Asia Society for Transportation Studies, 6, pp. 3077-3089.

Yin, Y. and Lawphongpanich, S. (2006) Internalizing emission externality on road networks. Transportation Research Part D, 11, pp. 292-301.

Yin, Y. and Lu, H. (1999) Traffic equilibrium problems with environmental concerns. Journal of Eastern Asia Society for Transportation Studies, 3, pp. 195-206.

Zalinger, M., Ahn, T.L. and Hausberger, S. (2005) Improving an instantaneous emission model for passenger cars, in Proceedings of the 14th Symposium Transport and Air Pollution 1 (June 1-3, 205 Graz Austria), pp. 167-176.

Zhang, C., Chen, X. and Sumalee, A. (2011) Robust Wardrop's user equilibrium assignment under stochastic demand and supply: expected residual minimization approach. Transportation Research Part B, 45, pp. 534-552.

Zhang, H., Gao, Z. and Zhang, B. (2006) Model and algorithm of transportation network design for emission reduction. Tumu Gongcheng Xuebao (China Civil Engineering Journal), 39, pp. 114-119 (in Chinese).

Zhang, H.M., Ritchie, S.G. and Jayakrishnan R. (2001) Coordinated traffic-responsive ramp control via nonlinear state feedback. Transportation Research Part C, 9, pp. 337-352.

Zhang, Y., Lv, J. and Ying, Q. (2010) Traffic assignment considering air quality. Transportation Research Part D, 15, pp. 497-502.

Zhao, T. and Gao, Z. (2006) The combined problem of the comprehensive discrete network design under environment restraints and optimal signal controls. Tumu Gongcheng Xuebao (China Civil Engineering Journal), 39, pp. 102-106 (in Chinese).

Zhong, R.X., Sumalee, A. and Maruyama, T. (2011) Dynamic marginal cost, access control, and pollution charge: a comparison of bottleneck and whole link models. Journal of Advanced Transportation, Accepted.

Zhou, S., Yan, X. and Wu, C. (2008) Optimization model for traffic signal control with environmental objectives, in Proceedings of the 4th International Conference on 
Natural Computation (October 18-20, 2008 Jinan China), pp. 530-534. 
Table 1. A comparison of existing emission models

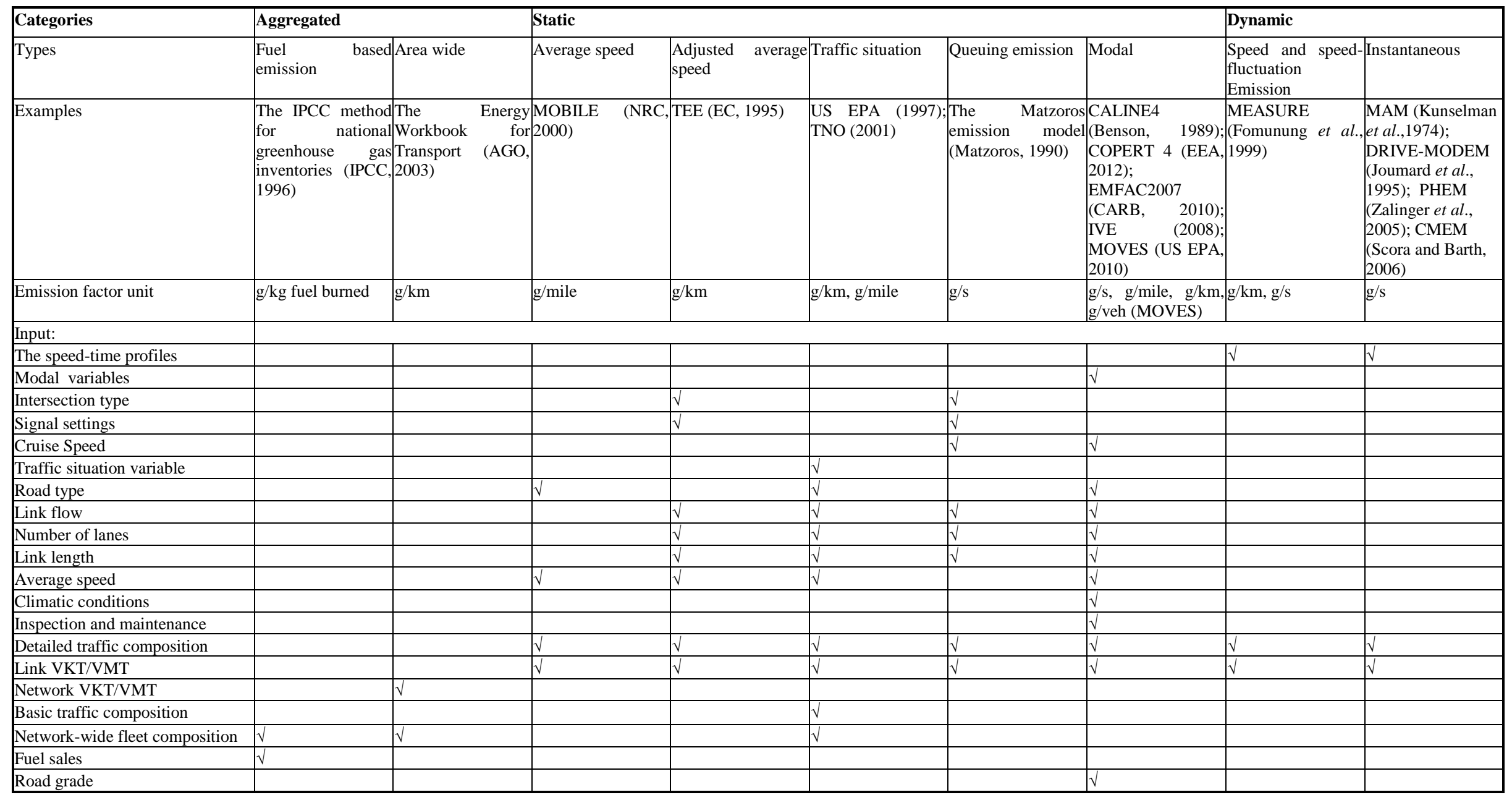

Acronyms used: CALINE4, CAlifornia LINE Source Dispersion Model version 4; CMEM, Comprehensive Modal Emissions Model; COPERT 4, Computer Programme to calculate Emissions from Road Transport version 4; DRIVE-MODEM, MODelling of EMissions and fuel consumption in urban areas, derived from the DRIVE research program; EEA, European Environment Agency; EMFAC2007, the EMission FACtors model 2007; IPCC, the Intergovernmental Panel on Climate Change; IVE, International Vehicle Emissions; MAM, Modal Analysis Model; MEASURE, the Mobile Emissions Assessment System for Urban and Regional Evaluation model; MOVES, MOtor Vehicle Emission Simulator; PHEM, the Passenger car and Heavy-duty vehicle Emission Model; TEE, Traffic Energy and Emissions model; TNO, Netherlands Organization for Applied Scientific Research; US EPA, the United States Environmental Protection Agency. 
Table 2. A comparison of various speed-based noise models

\begin{tabular}{|c|c|c|c|c|c|c|c|c|}
\hline Models & CoRTN & StL & RLS & CNR & ASJ & MITHRA & $\begin{array}{l}\text { NMPB- } \\
\text { Routes }\end{array}$ & $\begin{array}{l}\text { FHWA } \\
\text { TNM }\end{array}$ \\
\hline References & $\begin{array}{l}\text { DOT } \\
(1988) \\
\end{array}$ & $\begin{array}{l}\text { EMPA } \\
(1987) \\
\end{array}$ & RLS 1990 & $\begin{array}{l}\text { Cocchi et } \\
\text { al. (1991) }\end{array}$ & $\begin{array}{l}\text { Yamamoto } \\
(2010)\end{array}$ & $\begin{array}{l}\text { MITHRA } \\
(2011) \\
\end{array}$ & $\begin{array}{l}\text { Dutilleux et } \\
\text { al. (2008) }\end{array}$ & $\begin{array}{l}\text { FHWA } \\
(2011) \\
\end{array}$ \\
\hline $\begin{array}{ll}\text { Country of } \\
\text { origin }\end{array}$ & UK & Switzerland & Germany & Italy & Japan & France & France & USA \\
\hline Output & $L_{10}$ & $L_{e q}$ & $L_{e q}$ & $L_{e q}$ & $L_{e q}, L_{50}$ & $L_{e q}$ & $L_{e q}$ & $L_{e q}$ \\
\hline \multicolumn{9}{|l|}{ Inputs: } \\
\hline Speed & $\sqrt{ }$ & $\sqrt{ }$ & $\sqrt{ }$ & $\sqrt{ }$ & $\sqrt{ }$ & $\sqrt{ }$ & $\sqrt{ }$ & $\sqrt{ }$ \\
\hline Distance & $\sqrt{ }$ & $\sqrt{ }$ & $\sqrt{ }$ & $\sqrt{ }$ & $\sqrt{ }$ & $\sqrt{ }$ & $\sqrt{ }$ & $\sqrt{ }$ \\
\hline Gradient & $\sqrt{ }$ & $\sqrt{ }$ & $\sqrt{ }$ & $\sqrt{ }$ & $\sqrt{ }$ & $\sqrt{ }$ & $\sqrt{ }$ & $\sqrt{ }$ \\
\hline $\begin{array}{l}\text { Heavy vehicle } \\
\text { \& automobile }\end{array}$ & $\sqrt{ }$ & $\sqrt{ }$ & $\sqrt{ }$ & $\sqrt{ }$ & $\sqrt{ }$ & $\sqrt{ }$ & $\sqrt{ }$ & $\sqrt{ }$ \\
\hline Medium vehicle & & & & & $\sqrt{ }$ & & & $\sqrt{ }$ \\
\hline $\begin{array}{ll}\text { Bus } & \text { and } \\
\text { motorcycle } & \\
\end{array}$ & & & & & & & & $\sqrt{ }$ \\
\hline Tram/light rail & & $\sqrt{ }$ & & & & & & \\
\hline Railways & & $\sqrt{ }$ & & & & $\sqrt{ }$ & & \\
\hline $\begin{array}{l}\text { Unknown } \\
\text { traffic flow }\end{array}$ & & $\sqrt{ }$ & $\sqrt{ }$ & & & $\sqrt{ }$ & & \\
\hline Vehicle \% mix & $\sqrt{ }$ & & $\sqrt{ }$ & $\sqrt{ }$ & $\sqrt{ }$ & $\sqrt{ }$ & $\sqrt{ }$ & $\sqrt{ }$ \\
\hline Speed limit & & & $\sqrt{ }$ & & & & & \\
\hline $\begin{array}{l}\text { Uphill and hill } \\
\text { flow }\end{array}$ & & $\sqrt{ }$ & & & & & & \\
\hline $\begin{array}{l}\text { Traffic } \\
\text { interruption }\end{array}$ & & $\sqrt{ }$ & $\sqrt{ }$ & $\sqrt{ }$ & $\sqrt{ }$ & $\sqrt{ }$ & & $\sqrt{ }$ \\
\hline $\begin{array}{l}\text { Road surface } \\
\text { type }\end{array}$ & $\sqrt{ }$ & $\sqrt{ }$ & $\sqrt{ }$ & $\sqrt{ }$ & $\sqrt{ }$ & $\sqrt{ }$ & $\sqrt{ }$ & $\sqrt{ }$ \\
\hline $\begin{array}{l}\text { Ground surface } \\
\text { nature }\end{array}$ & $\sqrt{ }$ & $\sqrt{ }$ & $\sqrt{ }$ & $\sqrt{ }$ & $\sqrt{ }$ & $\sqrt{ }$ & $\sqrt{1}$ & $\sqrt{1}$ \\
\hline $\begin{array}{l}\begin{array}{l}\text { Presence } \\
\text { obstacles }\end{array} \\
\end{array}$ & $\sqrt{ }$ & $\sqrt{ }$ & $\sqrt{ }$ & $\sqrt{ }$ & $\sqrt{ }$ & $\sqrt{ }$ & $\sqrt{ }$ & $\sqrt{ }$ \\
\hline Car parks & & & $\sqrt{ }$ & & & & & \\
\hline $\begin{array}{l}\text { Meteorological } \\
\text { conditions }\end{array}$ & & & $\sqrt{ }$ & & $\sqrt{ }$ & $\sqrt{ }$ & $\sqrt{ }$ & $\sqrt{ }$ \\
\hline $\begin{array}{l}\text { Traffic } \\
\text { type }\end{array}$ & & & $\sqrt{ }$ & & $\sqrt{ }$ & $\sqrt{ }$ & & $\sqrt{ }$ \\
\hline Time-of-day & & & $\sqrt{ }$ & & & & & \\
\hline
\end{tabular}

Acronyms used: ASJ, Acoustical Society of Japan; CNR, Consiglio Nazionale delle Ricerche; CoRtn, Calculation of Road Traffic Noise; FHWA, Federal Highway Administration; NMPB-Routes, Nouvelle Méthode de Prevision du Bruit des Routes; RLS, Richtlinien für den Lärmschutz an Strassen; StL, French Calculation of Road Traffic Noise Model for Computers; TNM, Traffic Noise Model. 
Table 3. Summary of BTPE

\begin{tabular}{|c|c|c|c|c|c|c|}
\hline \multirow[t]{2}{*}{ References } & \multirow[t]{2}{*}{ Problem } & \multirow{2}{*}{$\begin{array}{l}\text { Focus } \\
\text { of ES }\end{array}$} & \multicolumn{2}{|c|}{ How to capture ES } & \multirow[t]{2}{*}{ Objective function(s) or type of environmental constraints used } & \multirow[t]{2}{*}{ Solution method } \\
\hline & & & $\begin{array}{l}\text { Objective } \\
\text { function }\end{array}$ & Constraint & & \\
\hline Kim and Kim (2006) & \multirow[t]{9}{*}{ RNEP } & E & $\sqrt{1}$ & & $\begin{array}{l}\text { Sum of highway maintenance, emission, accident, vehicle operation, and network } \\
\text { travel time costs }\end{array}$ & GA and bit comparison algorithm \\
\hline Mathew and Sharma (2006) & & E & & $\sqrt{ }$ & User equilibrium constraint with the sum of travel time costs and emission toll charges & GA \\
\hline Qiu and Chen (2007) & & EP & $\sqrt{ }$ & & $\begin{array}{l}\text { Sum of network travel time, investments, environmental pollution, land use, and } \\
\text { energy consumption costs }\end{array}$ & $\begin{array}{l}\text { An algorithm based on extremal } \\
\text { optimization }\end{array}$ \\
\hline Duthie and Waller (2008) & & EJ & $\sqrt{ }$ & & Four travel time related functions to measure equity & Selectorecombinative GA \\
\hline Huang et al. (2009) & & $\mathrm{N}$ & & $\sqrt{ }$ & Constraint of traffic noise pollution & PSO \\
\hline Jaber (2009) & & $\mathrm{E}$ & & $\sqrt{ }$ & Link emission constraint & GRG \\
\hline Jia et al. (2009) & & E & $\sqrt{ }$ & & Cumulative costs including emission cost over the modeling horizon & GA, SA and ABC \\
\hline Ferguson et al. (2010) & & $\mathrm{E}$ & $\sqrt{ }$ & & Total network emissions & GA \\
\hline Chen and Zhou Xu (2012) & & $\mathrm{E}$ & $\sqrt{ }$ & & $\begin{array}{l}\text { Total carbon monoxide (CO) emissions; total travel time; maximum ratio of origin- } \\
\text { destination travel times after and before capacity enhancement }\end{array}$ & Simulation-based GA \\
\hline Yin and Lu (1999) & \multirow[t]{12}{*}{ TDP } & $\mathrm{E}$ & $\sqrt{ }$ & & Total CO emissions & GA \\
\hline Nagurney (2000c) & & $\mathrm{E}$ & & $\sqrt{ }$ & User equilibrium constraint with congestion and emission costs & Modified projection method \\
\hline Hizir (2006) & & $\mathrm{E}$ & $\sqrt{ }$ & & Sum of all pollutants in the network & The GAMS/NLPEC solver \\
\hline $\begin{array}{l}\text { Yin and Lawphongpanich } \\
\text { (2006) }\end{array}$ & & $\mathrm{E}$ & $\sqrt{ }$ & & Total travel time and total traffic emissions & GA \\
\hline Li et al. (2007) & & $\mathrm{E}$ & & $\sqrt{ }$ & Link emission constraint & GRG \\
\hline Jaber and O’Mahony (2009) & & $\mathrm{E}$ & & $\sqrt{ }$ & Multiclass stochastic equilibrium constraint with congestion and emission costs & GRG \\
\hline Jakkula and Asakura (2009) & & $\mathrm{E}$ & & $\sqrt{ }$ & Environmental capacity constraint & Augmented Lagrangian dual algorithm \\
\hline Guo and Huang (2010) & & E \& N & & $\sqrt{ }$ & User equilibrium constraint with congestion and emission costs & Newton-Raphson’s method \\
\hline Yang et al. (2010) & & $\mathrm{E}$ & & $\sqrt{ }$ & Environmental capacity constraint & $\begin{array}{l}\text { Iterative two-stage adjustment } \\
\text { algorithm }\end{array}$ \\
\hline Sharma and Mishra (2011) & & $\mathrm{E}$ & $\sqrt{ }$ & $\sqrt{ }$ & $\begin{array}{l}\text { Total network emissions; weighted sum of network emissions and travel time; total } \\
\text { network emission constraint; link emission constraint }\end{array}$ & GA \\
\hline Zhong et al. (2011) & & $\bar{E}$ & & $\sqrt{ }$ & Access constraint (dynamic environmental capacity constraint) & $\begin{array}{l}\text { Euler scheme, SQP \& Padé } \\
\text { approximant }\end{array}$ \\
\hline Li et al. (2012) & & E & & $\sqrt{ }$ & Environmental capacity constraint & $\begin{array}{l}\text { Sample average approximation \& } \\
\text { sensitivity analysis-based methods }\end{array}$ \\
\hline Zhou et al. (2008) & CSCAP & E & $\sqrt{ }$ & & Total vehicle emissions at intersections & GA \\
\hline Lv et al. (2006) & RMP & E & $\sqrt{ }$ & & Weighted sum of network emissions and network travel cost & GA \\
\hline Yang et al. (2005) & \multirow[t]{2}{*}{ COCP } & E & & $\sqrt{ }$ & Environmental capacity constraint & Sensitivity analysis-based heuristic \\
\hline Feng et al. (2010) & & $\mathrm{E}$ & & $\sqrt{ }$ & Environmental capacity constraint & GA \\
\hline $\begin{array}{l}\text { Cantarella and Vitetta } \\
\text { (2006) }\end{array}$ & \multirow[t]{5}{*}{$\mathrm{CP}$} & E & $\sqrt{ }$ & & $\begin{array}{l}\text { Total travel time; total walking time; total CO emissions; number of vehicles that park } \\
\text { outside the desired destination; number of users that change their mode from car to bus }\end{array}$ & GA \\
\hline Zhang et al. (2006) & & $\mathrm{E}$ & $\sqrt{ }$ & & Weighted sum of total travel cost and total emissions in the network & PSO \\
\hline Zhao and Gao (2006) & & $\mathrm{E}$ & & $\sqrt{ }$ & Signalized, environmental capacity constraint & The branch-and-bound method \\
\hline Dimitriou et al. (2009) & & E & $\sqrt{ }$ & & Total travel cost; construction cost minus toll revenue; network $\mathrm{CO}_{2}$ emissions & GA \\
\hline Huang et al. (2010) & & E & $\sqrt{1}$ & & Total network emissions from junctions and road sections & PSO \\
\hline
\end{tabular}

Acronyms used: ABC: artificial bee colony algorithm; COCP: the car ownership control problem; CP; the combined problem; CSCAP; the combined signal control and assignment problem; E: emissions; EJ:

environmental justice; EP: environmental pollution; GA: genetic algorithm; GRG: the generalized reduced gradient algorithm; N: Noise; PSO: particle swarm optimization algorithm; RMP: the ramp metering problem; RNEP: the road network expansion problem; SA: simulated annealing; SQP; Sequential quadratic programming technique; TDP: the toll design problem. 